01

\title{
Исследование спектров гигантского комбинационного рассеяния гидрохинона, адсорбированного на диоксиде титана
}

\author{
(C) А.М. Полуботко ${ }^{1}$, В.П. Челибанов ${ }^{2, \text { ฯ }}$ \\ ${ }^{1}$ Физико-технический институт им. А.Ф. Иофрфе РАН, \\ 194021 Санкт-Петербург, Россия \\ ${ }^{2}$ Университет ИТМО, \\ 197101 Санкт-Петербург, Россия \\ ฯ e-mail: alex.marina@mail.ioffe.ru; Chelibanov@gmail.com
}

Поступила в редакцию 27.04.2017 г.

\begin{abstract}
В работе анализируется спектр гигантского комбинационного рассеяния (ГКР) гидрохинона, адсорбированного на наночастицах диоксида титана $\mathrm{TiO}_{2}$. Указывается, что усиление тем больше, чем больше средний размер наночастиц, что находится в согласии с электростатическим приближением. Кроме того, обнаружено, что в спектре появляются линии, запрещенные в обычном комбинационном рассеянии (КР). При этом усиление испытывают линии, обусловленные компонентами электрического поля, как нормальной, так и тангенциальной по отношению к поверхности. Этот результат является свойством, характерным для ГКР на полупроводниковых и диэлектрических подложках. Обнаружение запрещенных линий говорит о достаточно большой роли сильного квадрупольного взаимодействия в такой системе.
\end{abstract}

DOI: $10.21883 /$ OS.2018.01.45359.101-17

Исследование явления ГКР на полупроводниковых и диэлектрических подложках представляет большой интерес как с теоретической, так и с экспериментальной точек зрения. В [1] показано, что причиной ГКР в этом случае, как и в случае металла, является поверхностная шероховатость. Причем усиление происходит в малых областях поверхности с большой положительной кривизной. Нами было показано, что в случае ГКР на полупроводниках и диэлектриках усиление в этих областях меньше, чем на металле с таким же значением модуля диэлектрической проницаемости. Этот результат связан с тем, что диэлектрики и полупроводники в принципе прозрачны для электромагнитного поля в достаточно широкой области частот в отличие от металла, который стремится „вытолкнуть“ поле. Поэтому системы с полупроводниковыми или диэлектрическими подложками имеют „меньшую неоднородность“ среды в отличие от металла, что приводит к меньшему усилению поля и его производных. Однако в соответствии с экспериментальными и теоретическими результатами [1] в отличие от металла на шероховатых поверхностях полупроводников и диэлектриков должно происходить усиление как нормальной, так и тангенциальной компонент, что приводит к определенным особенностям в спектрах ГКР. Нами были исследованы спектры молекулы гидрохинона, адсорбированного на диоксиде титана $\mathrm{TiO}_{2}$. Как известно из литературы, гидрохинон представляет собой симметричную молекулу с группой симметрии $C_{2 h}$ (рис. 1). В соответствии с представлениями, изложенными в [2], он может образовывать молекулярный кристалл с триклинной или моноклинной сингонией. При этом молекулы гидрохинона образуют цепи, соединяясь друг с другом через атомы водорода. Исследование спектров комбинационного рассеяния и инфракрасного поглоще- ния показало [2], что колебательные частоты молекулы гидрохинона для обоих случаев очень близки между собой и близки также к частотам молекулы в паре или в растворе $\mathrm{CH}_{3} \mathrm{CN}$. Этот результат позволил нам использовать соотнесение линий неприводимым представлениям группы симметрии гидрохинона, полученное в [3-5] (таблица). Спектры гидрохинона, адсорбированного на коллоидных частицах $\mathrm{TiO}_{2}$ со средним размером 10 и $80 \mathrm{~nm}$ в интервале волновых чисел $600-1700 \mathrm{~cm}^{-1}$ показаны на рис. 2. Отметим, что спектры снимались для значения длины падающей волны $785 \mathrm{~nm}$. При этом коэффициент усиления составлял величину $\sim 10^{3}-10^{4}$. Описание спектрометра, на котором были получены экспериментальные данные, изложены в $[6,7]$.

По нашим представлениям гидрохинон адсорбируется параллельно поверхности наночастиц. Особенностью

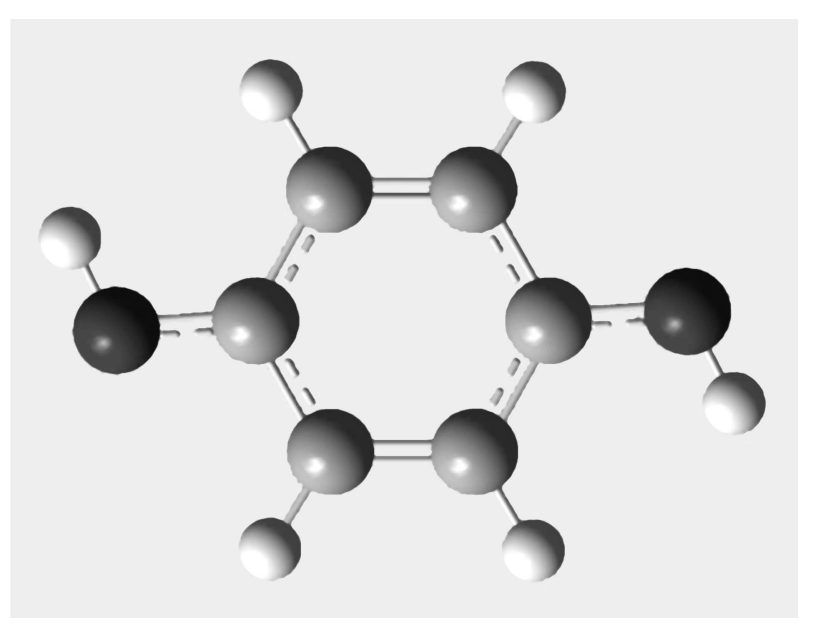

Рис. 1. Молекула гидрохинона. 
Соотнесение линий гидрохинона $\left(\mathrm{cm}^{-1}\right)$ в спектрах ГКР для наночастиц $\mathrm{TiO}_{2}$ со средними размерами 10 и $80 \mathrm{~nm}$

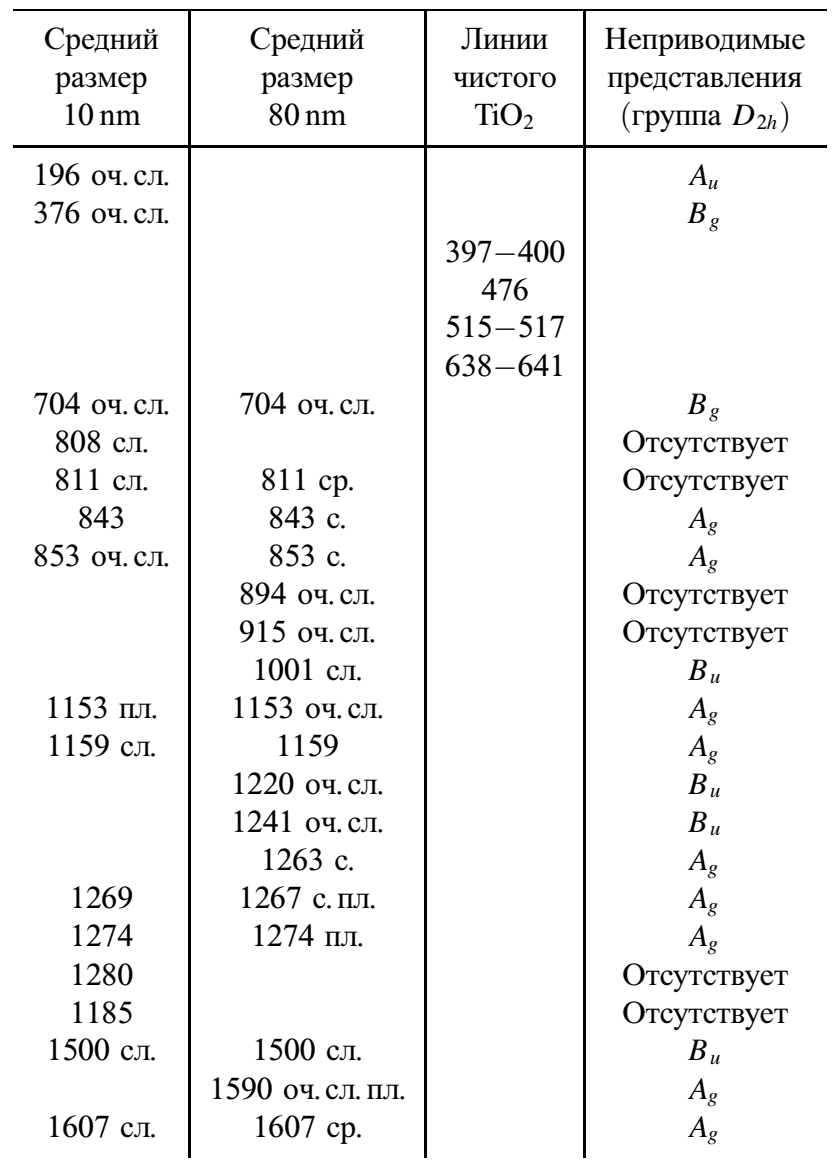

Примечание. с. - сильная, сл. - слабая, оч. сл. - очень слабая, пл. плечо.

спектра, снятого на частицах со средним размером $10 \mathrm{~nm}$, является появление дублетов в линиях с волновыми числами $(808,811)$ и $(1153,1159) \mathrm{cm}^{-1}$, а также достаточно широких полос и их тонкой структуры в районе 849 и $1270 \mathrm{~cm}^{-1}$. Достаточно большая ширина и тонкая структура полос, по-видимому, говорят о сильном взаимодействии молекулы с подложкой и существовании нескольких неэквивалентных положений молекулы. Для спектра, снятого для частиц $10 \mathrm{~nm}$, практически все линии относятся к колебаниям с единичным неприводимым представлением $A_{g}$ как и в обычном КР, однако одна линия с волновым числом $\sim 1500-1512 \mathrm{~cm}^{-1}$ относится к колебанию с неприводимым представлением $B_{u}$, описывающему трансформационные свойства компонент дипольного момента $d_{x}$ и $d_{y}$, параллельных поверхности. Появление этой линии, которая запрещена в спектре обычного КР, связано с возникновением в системе квадрупольного взаимодействия. Ее малая интенсивность указывает, что возникающее квадрупольное взаимодействие слабо в этой системе в отличие от случая с металлом. Кроме того, появление линии, относящейся к неприводимому представлению
$B_{u}$, указывает на справедливость нашего теоретического результата [1], указывающего на возможность усиления не только нормальной, но и тангенциальных компонент электрического поля в отличие от металлов, где такое усиление либо отсутствует, либо мало из-за высокой проводимости.

В случае больших частиц со средним размером $\sim 80 \mathrm{~nm}$ спектр ГКР усилен значительно сильнее. Этот результат объясняется тем, что находясь в области, в которой дифракция на наночастицах может быть описана в рамках электростатического приближения, интенсивность рассеяния должна быть больше для частиц больших размеров. В этом случае в спектре появляется еще несколько очень слабых запрещенных линий, относящихся к колебаниям с неприводимым представлением $B_{u}$, с волновыми числами 1001,1220 и $1241 \mathrm{~cm}^{-1}$. Кроме того, в спектре появляется также линия $704 \mathrm{~cm}^{-1}$, связанная с неприводимым представлением $B_{g}$.

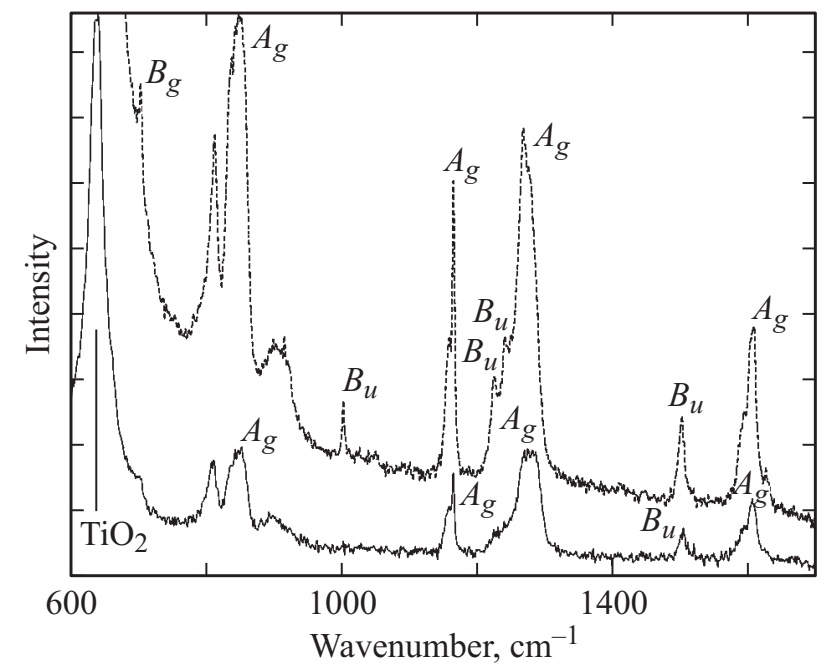

Рис. 2. Спектр ГКР гидрохинона, адсорбированного на наночастицах $\mathrm{TiO}_{2}$ со средними размерами 10 (сплошная кривая) и $80 \mathrm{~nm}$ (штриховая кривая) в диапазоне волновых чисел $600-1700 \mathrm{~cm}^{-1}$.

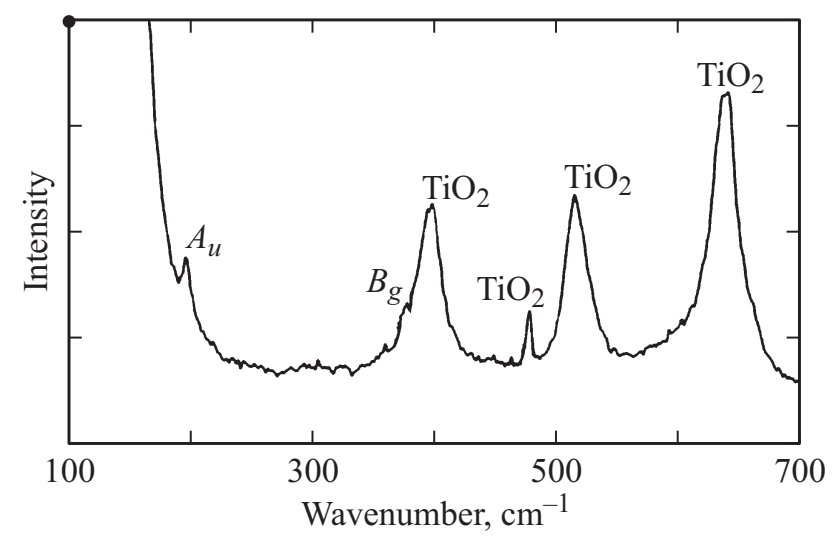

Рис. 3. Спектр ГКР гидрохинона, адсорбированного на наночастицах со средним размером $10 \mathrm{~nm}$ в диапазоне волновых чисел $100-700 \mathrm{~cm}^{-1}$. 
В области волновых чисел 100-700 $\mathrm{cm}^{-1}$ (рис. 3) спектр адсорбированного гидрохинона маскируется наложением сильных линий, принадлежащих колебаниям решетки $\mathrm{TiO}_{2}$, при значениях волновых чисел 397-400, $476,512-517$ и $638 \mathrm{~cm}^{-1}$. Однако в этой области видна одна слабая запрещенная линия при значении волнового числа $196 \mathrm{~cm}^{-1}$, относящаяся к колебаниям с неприводимым представлением $A_{u}$, и линия с неприводимым представлением $B_{g}$ при значении волнового числа $378 \mathrm{~cm}^{-1}$.

В целом исследование спектра гидрохинона указывает на правильность нашей теории ГКР на полупроводниковых и диэлектрических подложках [1] и необходимость учитывать квадрупольное взаимодействие, которое оказалось достаточно сильным в данной системе и привело к появлению слабых запрещенных линий.

\section{Список литературы}

[1] Полуботко А.М., Челибанов В.П. // Опт. и спектр. 2017. T. 122. № 6. C. 78.

[2] Kubinyi M.J., Keresztury G. // Spectrochim. Acta. A. 1989. V. 45. P. 421.

[3] Kubinyl M., Billes F., Grofcsik A., Keresztury G. // J. Mol. Str. 1992. V. 266. P. 339

[4] Nonella M. // J. Phys. Chem. B. 1997. V. 101. P. 1235.

[5] Kubinyi M.J., Keresztury G. // Mikrochim. Acta. 1997. V. 14. P. 525.

[6] Iasenko E., Marugin A., Kozliner M. // Proc. $17^{\text {th }}$ Int. conf. „Laser Optics 2016“. 2016. St. Petersburg. P. 51.

[7] Iasenko E.A., Chelibanov V.P., Polubotko A.M. Электронный peсурс. Режим доступа: arXiv:1604.00497 